\title{
Psychiatric Challenges of HIV/AIDS and the Added Problems of Aging with Seropositive Status
}

\author{
James Paul Pandarakalam* \\ Consultant psychiatrist, Northwest Boroughs Health Care NHS Foundation Trust Hollins Park Hospital \& AFG Rehab Hospitals, UK
}

*Corresponding author: James Paul Pandarakalam, Consultant psychiatrist, Northwest Boroughs Health Care NHS Foundation Trust Hollins Park Hospital \& AFG Rehab Hospitals, Winnick Lane, Warrington, England, UK

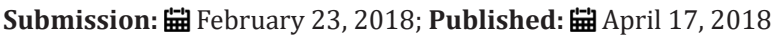

\begin{abstract}
AIDS psychiatry is an underserved area of health system. Sero-positive patients are at risk of developing psychiatric symptoms and disorders seen in the general population and ones related to HIV. A significant proportion of HIV patients have, or develop, mental health problems and those often have impact on HIV/AIDS treatment and adherence negatively. The presence of psychiatric disorder carries higher risk of HIV infection and worsens the prognosis of patients once they are infected. Mental health professional can reduce incidents of high-risk sexual behaviour thereby prevent transmission of infection and early detection of HIV among psychiatric population. Psychiatric professionals can help treatment adherence to medical regimes, increase the longevity and quality of life for people living with HIV/AIDS as well as controlling the spread of the disease. HIV sufferers are at higher risk of suicide soon after detection of the condition and at the later stage of AIDS. Highly active retroviral treatments have given the patients a new outlook towards life and their illness in developed countries, but the situation has not changed in under developed countries who are in the pre-HAART era. HIV positive patients are more vulnerable to drug interactions and psychiatric drugs can also interact with antiretroviral medications and the elderly patients are more vulnerable. HAART has increased the life span of patients and aging with HIV has become the norm. Aging is also associated with pharmacokinetic and pharmacodynamic deviations. HIV research has become the greatest successes story of modern medicine. There are common psychiatric issues for both the adult and the elderly patients and this paper discusses the psychiatric problems of HIV/ AIDS in general and in relation to psycho-geriatrics.
\end{abstract}

Keywords: HIV-AIDS-depression; AIDS; Dementia; Suicide; Psychotropics interactions; De-stigmatisation

\section{Introduction}

Psychiatric disorders are common in patients with HIV, who may lack optimal care because their psychiatric disorders are a barrier to medical care [1]. Because of the fact that psychiatric patients, especially those with substance abuse disorders are at high risk for HIV infection, mental health professionals are always on the front lines of AIDS pandemic. HIV sero-prevalence among persons with severe mental illness has been noted to be around $4 \%$ to $23 \%$ compared with $0.4 \%$ in the general population [2]. Recent scientific advances have markedly enhanced the quantity and quality of life for many of those who are part of the HIV/ AIDS epidemic and most patients with newly diagnosed infection should prepare for a normal, healthy and productive life $[3,4]$. A recent study proposed that over 4.2 million people living with HIV worldwide are aged over 50 [5]. In many clinical settings, cures may be an exception, chronicity is the norm. This is particularly true of HIV/AIDS. A US study found a 12-month prevalence of nearly $50 \%$ for psychiatric illness among the selected sero-positive individuals [6]. Patients are at risk of developing psychiatric symptoms and disorders seen in the general population and ones related to HIV. HIV/AIDS have multiple psychiatric manifestations (Table 1).

Table1: Psychiatric Significances of HIV/AIDS.

\begin{tabular}{|l|l|}
\hline S.no & Psychiatric Significances of HIV/AIDS \\
\hline 1 & $\begin{array}{l}\text { Serious emotional reactions consequent to sero-positive } \\
\text { diagnosis }\end{array}$ \\
\hline 2 & Neurocognitive changes as side effects of HIV infection \\
\hline 3 & $\begin{array}{l}\text { Opportunistic neurological and systemic infections } \\
\text { and their treatments leading to neuropsychiatric } \\
\text { complications }\end{array}$ \\
\hline 4 & $\begin{array}{l}\text { Psychiatric side effects of highly active anti-retroviral } \\
\text { therapy }\end{array}$ \\
\hline 5 & $\begin{array}{l}\text { Vulnarability posing risks to patients suffering from } \\
\text { severe mental illness }\end{array}$ \\
\hline 6 & Direct and indirect links of substance abuse \\
\hline 7 & Treatment of HIV/AIDS and adherence \\
\hline 8 & Existential crisis \\
\hline 9 & Mental capacity \\
\hline
\end{tabular}




\begin{tabular}{|l|l|}
\hline 10 & Initiation of partner notification \\
\hline 11 & Assisted suicide and voluntary euthanasia \\
\hline
\end{tabular}

Health professionals dealing with sero-positive patients confront a variety of psychiatric disorders: intravenous drug abuse or bipolar disorder (BD) may place a patient at risk of HIV; depression, anxiety disorder or dementia may relate to an HIV diagnosis or HIV progression; vivid dreams or decreased concentration may be associated with the initiation of efavirenz [7].

A significant proportion of HIV patients have, or develop, mental health problems and those often have impact on HIV/AIDS treatment and adherence negatively. Missed doses of highly active antiretroviral therapy (HAART) can increase the chance of the HIV virus developing resistance and recognizing factors that promote treatment adherence is of paramount importance in improving overall outcome $[8,9]$. Psychiatrists could help to enhance treatment adherence and decrease morbidity and mortality [10]. Integrating psychiatric and psychosocial interventions would benefit the mental and physical health of those living with HIV/AIDS [11] Psychiatric input is valuable in every phase of the illness (Table 2).

Table 2: Different phases of HIV infection for Psychiatric Interventions

\begin{tabular}{|c|c|}
\hline S.NO & $\begin{array}{c}\text { Different Phases of HIV Infection for Psychiatric } \\
\text { Interventions }\end{array}$ \\
\hline 1 & Identification of risk behaviours \\
\hline 2 & Exposure and acute sero-conversion illness \\
\hline 3 & Anticipation of HIV testing \\
\hline 4 & Confirmation with a positive antibody test \\
\hline 5 & Changes in social and personal identity \\
\hline 6 & Entry into health care system \\
\hline 7 & Managing compliance with antiretroviral regime \\
\hline 8 & $\begin{array}{c}\text { The asymptomatic latent phase or the minor symptomatic } \\
\text { phase }\end{array}$ \\
\hline 9 & Onset of the major symptomatic phase and opportunistic \\
\hline 10 & AIDS-defining conditions: the severe symptomatic phase \\
\hline 11 & Anticipatory grief and bereavement due to the loss of self \\
\hline 12 & Late stage AIDS to end stage \\
\hline
\end{tabular}

\section{Aging with HIV}

UNAIDS and WHO estimate that of the 40 million people living with HIV/AIDS in the world, approximately 2.8 million are 50 years and older. With the introduction of highly active antiretroviral therapy (HAART), survival following HIV diagnosis has risen dramatically and HIV infection has evolved from an acute disease process to being managed as a chronic medical condition. As treated HIV-infected patients live longer and the number of new HIV diagnoses in older patients rise, living with HIV has become much commoner among the elderly population than a few decades ago. Since effective ART became available in the mid-1990s, the life expectancy of people living with HIV has increased - about 12 million life years were gained in 1996-2008 through wider access to ART. It has allowed individuals diagnosed at a young age to live longer, a factor in the ageing of patients associated with HIV/AIDS. By 2018, 50\% of people living with HIV and undergoing clinical treatment will be over 50. An estimate shows that the percentage of people living with HIV aged 50 years and above had increased to more than $17 \%$ over the past decade [12]. In sub-Saharan Africa, estimates show that the percentage will triple by the year 2040 [13].

Table 3: Existential Postures.

\begin{tabular}{|c|c|}
\hline S.No & Existential Postures \\
\hline 1 & Confusion versus coherence \\
\hline 2 & Isolation versus communion. \\
\hline 3 & Despair versus hope. \\
\hline 4 & Hopelessnes versus agency \\
\hline 5 & Meaninglessness versus purpose. \\
\hline 6 & Cowardice versus courage. \\
\hline 7 & Resentment versus gratitude. \\
\hline
\end{tabular}

The above situations present additional challenges - such as that HIV diagnosis tends to be delayed in older patients because symptoms may be confused with those of other diseases common to them (Table 3). Griffith \& Gaby [14] have identified seven existential postures of vulnerability and resilience that are of great value in psychotherapeutic interventions in the context of positive sero-positive status notification in the elderly [14].

Healthcare professionals do not consider the elderly population to be at high risk of HIV infection because of a mistaken belief that they cease sexual activity. The elderly think AIDS is not a problem for them despite contrary evidence. For older individuals with HIV there is a further challenge - they have higher susceptibility to the toxic effects and pharmacological interactions of medications. The quality of life of the HIV patient is much lower than that of peers without HIV because of the stigma of HIV, ageism and, sometimes, homophobia. For some, cognitive impairment complicates the problem of non-adherence to ART and reckless sexual activity.

A retrospective analysis of senior patients who were hospitalised and 60 years older at time of death and apparently had no history of HIV or AIDS, $6.2 \%$ of men and $8.9 \%$ of women were found to be HIV-seropositive [15]. In the CDC 2006 National Health Interview Survey, adults 65 years and older had the lowest HIV testing rates (only $11.4 \%$ had ever had an HIV test) compared to other age groups (the highest rate being 53.5\% among adults 25 to 34 years old). Misconceptions about HIV infection and who it affects, denial of risk factors, sense of hopelessness even if HIVpositive status was known, and active drug use are the main factors which might hinder older adults from seeking an HIV test [16].

HIV associated morbidity and mortality was observed to be higher in elderly patients as compared to their younger counterparts $[17,18]$ and aging is also associated with rapid progression to AIDS $[19,20]$. Several reports have demonstrated impaired immune recovery in elderly patients [21]. Elderly patients compared to younger patients respond poorly to HAART. 
Advancing age is also associated with pharmacokinetic (drug absorption, distribution, metabolism, and excretion) and pharmacodynamic deviations (the effect of a drug on its target site). Pharmacokinetic changes include a reduction in renal and hepatic clearance and an increase in volume of distribution of lipid soluble drugs (hence prolongation of elimination half-life) whereas pharmacodynamic changes involve altered (usually increased) sensitivity to several classes of drugs such as anticoagulants, cardiovascular and psychotropic drugs. In terms of pharmacokinetic changes, aging particularly slows hepatic metabolism. However, liver function tests are poorly correlated with drug metabolizing activity. Normal aging does affect oxidation reactions, but it does not affect glucuronidation reactions. In general, psychotropic drugs metabolized by glucuronidation are preferred in the elderly. Among other pharmacodynamic alterations noted in the aging process, reduction of M1 signal transduction is significant. This makes elderly patients more sensitive to anticholinergic effects. Moreover, senior patients are more sensitive to the interaction of psychotropics with HAART.

\section{Diagnosis-related anxieties}

The clinician's inability to deal with patients' anxieties sometimes blocks a timely diagnosis. A person is often examined over years for various medical problems; many tests are done but clinicians are reluctant to suggest an HIV test. The individual finally presents with serious complications, an HIV test is done and the return is positive. Patients who have been unaware of their HIV status and ignorant and fearful about it often spread the infection more than others. Fear and denial are the most common barriers to HIV testing [22].

Table 4: Pre-test Counselling.

\begin{tabular}{|c|c|}
\hline S. No. & Pre-Test Counselling \\
\hline 1 & $\begin{array}{c}\text { Ensure the person has a full understanding of the implications } \\
\text { of the test and are able to make an informed decision about } \\
\text { whether to test. }\end{array}$ \\
\hline 2 & Ensure informed consent is gained from the person \\
\hline 3 & $\begin{array}{c}\text { Give the person an opportunity to discuss routes of HIV } \\
\text { transmission }\end{array}$ \\
\hline 4 & $\begin{array}{c}\text { Discuss the implications and support needs that may follow } \\
\text { either with a positive or negative test result. Offer also } \\
\text { information about the efficacy of currently available anti- } \\
\text { retroviral drugs. }\end{array}$ \\
\hline 5 & $\begin{array}{c}\text { Consider ways to reduce transmission or contact of the virus } \\
\text { in the future. }\end{array}$ \\
\hline 6 & $\begin{array}{c}\text { Encourage the person to consider and evaluate the result may } \\
\text { have on the person's emotional, physical and in relation to the } \\
\text { life style. }\end{array}$ \\
\hline
\end{tabular}

Until the introduction of HAART in mid-nineties, a diagnosis of HIV was perceived as a near-death sentence. Those who receive positive and negative results should have counselling because life-style changes may be indicated (Table 4). Some people are so anxious that they repeat antibody tests weekly after negative results. Those results may reinforce the myth that it cannot happen to them, so they continue risky sexual behaviour. People with negative tests must remain negative; to do that they need guidance. With the introduction of HAART and a dramatic decrease in morbidity and mortality, research findings reflect a changing picture in the attitude towards HIV testing and the pervasive and high levels of distress previously associated with sero-positivity appear to be easing [23]. But the psychological reactions reported in the pre-HAART era still prevail in underdeveloped countries. It is highly important to discuss the efficacy of the currently available anti-retroviral drugs to the patients when the positive results of HIV testing are disclosed or even at the pre-test counselling.

Individuals develop a sense of demoralisation similar to a depressive reaction soon after a sero-positive test, but the responsively of mood is usually preserved [14]. They can exhibit strong emotional and psychosocial responses to a serological diagnosis of HIV infection. Short-term emotional responses include surprise, denial, confusion, distress, sadness, disappointment and even relief. Short-term psychosocial responses include fear of telling sexual partners, anger with the source partner, guilt about acquiring or transmitting HIV and concern about transmission to a child. Ongoing responses include fear of telling future and existing sexual partners, feeling sexually undesirable or socially stigmatised and sexual avoidance. HIV positive women are reported to experience even higher levels of psychological distress than HIV positive men [24]. Fear of transmission to a baby and relationship concerns remain in the mind, but many negative responses are time limited and potentially amenable to counselling.

\section{Psychiatric morbidity}

Patients living with HIV/AIDS have to cope with perpetual stressors. They have to brace themselves to face their declining health, changeability of disease progression, regular haematological investigations, insomnia, chronic pain, physical wasting, chronic diarrhoea, medication side effects, disclosure of HIV status and consequent loss of vital human relationships, financial losses, social discrimination, cognitive decline and opportunistic infections [25]. Even without opportunistic infections, HIV brain infection causes severe neuro-behavioural syndromes such as dementia by complex interaction with host molecules and non-neuronal cells. The neuro-physiological and psychological stress of HIV infection may aggravate underlying psychotic illness by acting on the brain physiology.

HIV-related psychiatric problems have a common global pattern. A South African study concluded that rates of mental disorder are substantially higher in people with HIV/AIDS than in the general population of developing countries and similar to HIV positive groupings in developed countries [26]. For the psychiatrist, substance dependency, depression, anxiety, delirium, dementia, post-traumatic stress disorder, suicide and other co-morbid disorders are among the common clinical challenges (Table 5). 
Table 5: HIV/AIDS Psychiatric problems.

\begin{tabular}{|c|c|}
\hline S.No. & HIV/AIDS Psychiatric problems \\
\hline 1 & Neuropsychiatric disorders-Dementia, Delirium \\
\hline 2 & $\begin{array}{c}\text { HIV and Co-morbid psychiatric disorders- Primary } \\
\text { psychiatric condition complicating HIV and HIV complicating } \\
\text { primary psychiatric disorder. }\end{array}$ \\
\hline 3 & Pain syndrome \\
\hline 4 & Acute stress reaction \\
\hline 5 & Fear \\
\hline 6 & Anger \\
\hline 7 & Panic feelings \\
\hline 8 & Sense of being overwhelmed \\
\hline 9 & Chronic Stress reaction due to HIV \\
\hline 10 & Depression, \\
\hline 11 & Anxiety, \\
\hline 12 & Substance dependency, \\
\hline 13 & PTSD \\
\hline 14 & Hopelessness and helplessness -suicide \\
\hline
\end{tabular}

\section{Suicide}

Suicidal behaviour is a major concern in sero-positive individuals globally, and healthcare professionals should be alert to the suicide risk in HIV-positive patients. It is highest soon after an HIV-positive test [27], and at the onset of AIDS symptoms. Those in midlife and older who live with HIV/AIDS especially experience significant emotional distress and suicidal thoughts. They require targeted intervention to improve their mental health. Gay people may intentionally contract HIV as a form of suicide. However many patients develop coping strategies as time goes by; the risk of suicide peaks again when they start developing AIDS symptoms [28].

\section{Depression}

Older adults with HIV are more prone to develop depression than the general population. Studies indicate that the prevalence of major psychiatric disorders in persons living with HIV is 30$60 \%$ [29]. As many as $10 \%$ of adults 60 years of age or older who are seen in primary care settings have clinically significant depression. A complex antiretroviral therapy (ART) regimen, the onset of AIDS-related illness and late- to end-stage AIDS all necessitate specialised psychiatric help. A US study showed that the frequency of major depressive disorder was nearly twice as high in HIV-positive subjects than in HIV-negative comparison subjects; and that although most HIV-positive individuals appear to be psychologically resilient there is a strong association between HIV and major depressive disorder [30]. The diagnosis of major depression in HIV clinic is complicated by the high incidence of depressive symptoms that are normally linked with chronic illness, isolation and serious losses, and complex medical treatments; comorbid neurological illness, co-morbid substance misuse and the use of other medications affecting mental state further obscure the clinical picture [8].

\section{Bipolar disorder}

BD has a significant prevalence among HIV/AIDS sufferers - about 2.6\% [31]. BD patients are more prone to risky sexual behaviour than others, and among sero-positive individuals $1.2 \%$ have been recognised as suffering from secondary mania indicative of AIDS progression [32]. Secondary mania may also result from opportunistic infection; treatment with zidovudine, didanosine or clarithromycin; or efavirenz overdose. Such patients may not have a family history of BD or a previous history of it. Secondary manic syndromes are decreasing with the advent of HAART. It is known that BD patients in the manic or hypomanic phase are prone to risky sexual behaviour and may be infected with the HIV virus or transmit it to negative partners. They are more likely than others to report unprotected intercourse with HIV-negative partners and poor adherence to ART; to reduce their HIV transmission they need evaluation and prevention services.

\section{Schizophrenia}

Although there is no evidence to suggest that sero-positive patients are at higher risk of developing schizophrenia, data suggest higher prevalence of HIV/AIDS among schizophrenia sufferers. The late stage of the AIDS dementia complex may lead to psychotic conditions presenting as first-rank symptoms of schizophrenia [33]. The positive symptoms coupled with neuroleptic treatment may lead to sexual dysfunctions, but schizophrenia sufferers are sexually active and vulnerable to HIV infection. That is because their disadvantaged economic and social status, and their high incidence of homosexuality [34], substance abuse and homelessness, brings them into contact with high-risk populations. Restrictive institutionalisation, difficulty in maintaining heterosexual relations, delusional ideas and other social factors may contribute to maleto-male sexual expression among schizophrenia sufferers. The treatment of such patients does not differ significantly from noninfected patients, but potential interactions and adverse reactions of antipsychotics with HIV medications should be seriously considered.

\section{Substance Misuse}

Patients who have a triple health diagnosis of HIV, mental illness and drug addiction are not a rarity. Historically, injection drug use and commercial sex have been the major vectors of HIV transmission. Other recreational drugs of abuse have also contributed to HIV transmission by promoting high risk sexual behaviour. Alcohol is the most commonly used substance among the HIV infected and marijuana is the most frequently used drug. In a US sample of patients, $63 \%$ had used hard drugs sometimes in their lives and have become habitual users [35]. Such drug use has negative effect on adherence to ART. The life span of sero-positive individuals with drug abuse disorder are shorter than non-users and according to a US study four out of ten AIDS death is related to drug abuse.

Drug abuse and addiction may facilitate HIV transmission while providing a pathological coping strategy and also worsen 
HIV symptoms, causing greater neuronal injury and cognitive impairment. Alcohol abuse is associated with increased medical co-morbidities and non-adherence to ART. It is not yet clear how far drug abuse may contribute to the development of treatmentresistant viral strains of HIV. Treating drug abuse disorder is preventing HIV infection and transmission. Psycho-education seems to be the way forward. Methadone therapy for heroin addiction is found to reduce the injection drug use, and of sharing drugs and needles. Personality disorders are much higher among the HIV infected and they take the form of antisocial and borderline personality types [36]. This finding is in par with the observation that personality disorders have high rate of substance misuse problems which is a known risk factor for sero-positivity.

\section{Delirium - AIDS Dementia Complex}

Delirium involves global cognitive impairment and includes abnormalities of thought, perception and levels of awareness. It has an abrupt onset and is intermittent, often exhibiting psychomotor agitation. Often patient's exhibit features of both hypoactive and hyperactive delirium states. EEG and electrophysiological tests help its confirmation. It has a multi-factorial aetiology encompassing any condition that initiates disordered body chemistry, illness that compromises the body's circulation and oxygenation, medication with an effect on the CNS and infection of a patient in a high-risk group. It is a frequent, and under diagnosed, symptom of AIDS.

HIV-associated dementia, defined as acquired cognitive abnormality in two or more domains (Table 6), is associated with functional impairment and acquired motor or behavioural abnormality in the absence of aetiology. During the course of their illness $30-60 \%$ of patients experience CNS complications and $90 \%$ reveal neuro-pathological abnormalities at autopsy. A range of cognitive and behavioural symptoms manifest in the early stages, becoming more frequent in advanced cases. Evidence suggests that HIV begins to damage the brain within months of infection [37].

Table 6: Symptoms of HIV/AIDS Dementia Complex.

\begin{tabular}{|c|c|}
\hline S.No. & $\begin{array}{c}\text { Symptoms of HIV/AIDS } \\
\text { Dementia Complex }\end{array}$ \\
\hline 1 & Early Symptoms: \\
\hline 2 & Forgetfulness \\
\hline 3 & Impairment of concentration \\
\hline 4 & Slowing of thinking \\
\hline 5 & Confusion \\
\hline 6 & Slurred speech \\
\hline 7 & Loss of balance \\
\hline 8 & Mood swings \\
\hline 9 & Muscle weakness \\
\hline 10 & Clumsiness \\
\hline 11 & Coordination difficulties \\
\hline 12 & Deterioration in handwriting \\
\hline 13 & Delayed symptoms: \\
\hline 14 & Severe confusion \\
\hline
\end{tabular}

\begin{tabular}{|c|c|}
\hline 15 & Disorientation \\
\hline 16 & Convulsion \\
\hline
\end{tabular}

The pathogenesis of HIV in the CNS and the underlying mechanism leading to neurocognitive impairment is now well elucidated. HIV crosses the blood-brain barrier through a Trojanhorse-type mechanism using macrophages [38]. Once in the brain, HIV targets and infects glial cells, from which it later secretes neurotoxins that lead to neuronal damage and death [39]. Through post-mortem neuropathological examination of HIV patients, the presence of the virus in the frontal lobes, subcortical white matter and basal ganglia has been demonstrated [40]. Recent evidence supports a mechanism by which neurotoxins released by periventricular macrophages and microglia trigger cytokine and chemokine release [41], leading to modification of the synaptic architecture in the cortex [42]. HIV infects and destroys subcortical white matter, disrupting neural networks, signal transmission and frontal lobe function and resulting in cognitive and psychomotor slowing and impaired attention, concentration, judgement, impulse control and executive function [43].

Treatment of cognitive impairment and emotional sequalae are symptomatic and directed at prolonging normal cognitive functioning. Memory impairment may respond to acetylcholinestrase inhibitors, as in Alzheimer's disease. Earlier diagnosis of HIV and the introduction of HAART may reduce the severity of the process and has even induced full recovery from HIV-associated dementia [44,45]. Supportive psychotherapy may be effective for associated depressive symptoms. Useful neuropsychological tests include the HIV Dementia Rating Scale. Halstead finger-tapping test for motor Speed [46], and the Trail making test which assesses psychomotor speed [47] and sequencing ability [48]. Antiretroviral therapy appears to reduce the risk of HIV associated dementia. There are other neurocognitive abnormalities that have been found to be more common in HIV-infected elderly patients than in age matched HIV-negative patients. Studies show that elderly patients are at an increased risk of developing cognitive impairment as compared to younger patients [49]. In elderly patients, depressive symptoms and low $\mathrm{CD} 4$ count have been found to be the risk factors for cognitive impairment [50]. Besides the higher prevalence of dementia in older versus younger adults, differences also have been found in milder cognitive diagnoses, with $44.7 \%$ of the older group and $26.3 \%$ of the younger group meeting formal criteria for minor cognitive motor disorder.

\section{Pain Syndrome}

Clinically significant pain is a problem even in the preAIDS stage and has diverse aetiology. The most common pain syndromes include painful sensory peripheral neuropathy, pain due to extensive Kaposi's syndrome, headache, oral and pharyngeal pain, abdominal pain, arthralgia and myalgias, and painful dermatological conditions $[51,52]$ and these lead to psychological and functional morbidity. Treating pain in substance abusers can pose huge psychiatric challenges. At the present time, the guidelines developed for treatment of cancer pain are used in patients with 
HIV disease. A multidisciplinary approach to pain management is optimal, exploring the psychological and emotional contribution to pain. AIDS patients have a private fear of dying in pain. Along with various forms of analgesics, antidepressants are also commonly used to treat the pain in HIV/AIDS patients. Antiretroviral associated psychosis. There is also antiretroviral associated psychosis reported since the introduction of antiretroviral drugs (Table 7).

Table 7: Antiretroviral Associated Psychosis.

\begin{tabular}{|c|c|}
\hline S.No. & Antiretroviral Associated Psychosis \\
\hline 1 & Limted data- cased studies only and no controlled studies. \\
\hline 2 & Antiretrovirals are associated with psychosis \\
\hline 3 & Atypical psychotic features \\
\hline 4 & $\begin{array}{l}\text { First month of commencement of antiretrovirals are } \\
\text { crucial period. }\end{array}$ \\
\hline 5 & Combnation therapy appears riskier. \\
\hline 6 & $\begin{array}{l}\text { Resolution on withdrawal of the antiretroviral agent, but } \\
\text { highly frustrating for the patient. }\end{array}$ \\
\hline 7 & Antipsychotic drugs are helpful \\
\hline 8 & $\begin{array}{l}\text { Converesely also evidences are there that antiretrovirals } \\
\text { may protect against psychosis. }\end{array}$ \\
\hline
\end{tabular}

While various antiretroviral agents have undesirable physical side effects which are distressing to the patient and affect compliance and outcome, certain antiretroviral agents may precipitate psychiatric disorders in individuals with no previous psychiatric history in the form of first episode psychosis. Such incidence may not be common. The literature contains several reports dealing with psychosis that are thought to be due directly to antiretroviral therapy [53-57]. In such situations, it should be emphasised to susceptible patients that antiretroviral medications may induce a transient psychosis that can be readily treated, and patients should be reassured that such psychotic symptoms should not be assumed to be schizophrenia. The management of such cases should include mental health professionals. It is understandable the distress of the patient and the clinician if elderly patients who are prescribed antiretrovirals for the first time, develop this form of psychosis. Certain antiretroviral may protect against psychosis.

\section{Pharmaco-Therapeutic Challenges}

Mental health professionals are most often not well informed of the newly added anti-retroviral drugs to the HIV treatment regimen; awareness of them would increase the morale of the caregivers and reduce the fatality linked stigma associated with the infection. As mentioned before, advancing age involve pharmacokinetic and pharmacodynamic alterations. Managing medications and drugto-drug interactions is a complicated sub-specialty. Elderly HIV sufferers are normally on poly pharmacy as they also suffer from different co-morbid conditions. In one study that investigated HIVinfected individuals aged 55 years and older in New York City, 89\% had one or more comorbidities, or an average of 2.4 comorbid conditions per person, and $81 \%$ received medications unrelated to HIV [58]. The same study revealed that the most common comorbidities were hypertension, chronic obstructive pulmonary disease, and diabetes mellitus. Understandably, the elderly victims of this affliction are prescribed different interacting medications with a sensitive balancing dose. In general, there is little known about the impact of aging on medication use in HIV-infected individuals and the potential for interactions with HAART and co-administered medications as well as their impact on therapy tolerability and the response of the HIV virus to the blend of medications [59].

There are six classes of antiretroviral agents and the number is growing. ART includes protease inhibitors, nucleotide analogue reverse transcriptase inhibitors, non-nucleoside reverse transcriptase inhibitors, CCRS inhibitors, invirase inhibitors and fusion inhibitors. Nucleoside reverse transcriptase inhibitors (NRTIs) block the viral RNA to DNA transcription process by substituting in chain-terminating nucleosides (or nucleotides) in the DNA chain; non-nucleoside reverse transcriptase inhibitors (NNRTIs) change the conformation of the reverse transcriptase enzyme, rendering the enzyme dysfunctional; protease inhibitors (PIs) inhibit the protease enzyme which cleaves viral proteins into functional components prior to packaging into new HIV particles; fusion inhibitors which block the fusion of HIV with the host cell at the initial point of contact preventing HIV infection; entry inhibitors which block the entry of HIV into the host cell by blocking the cell-surface co-receptor CCR5; and integrase inhibitors prevent the integration of the viral DNA into the host genome. Some antiretroviral drugs have been combined into one pill, known as a "fixed dose combination". A discussion of the currently available anti-retroviral drugs is beyond the scope of this review. A number of non-HIV related medications can be affected by, or directly affect, HIV medications through drug-drug interactions, leading to either considerable toxicity or reduced efficacy of the target medications. Sero-positivity involves multi-morbidity making poly pharmacy unavoidable.

In poly pharmacy, there can be an increased risk of pharmacodynamic and pharmacokinetic interactions. Such a situation could lead to poor adherence to medication and impaired quality of life for patients. It is not clear how psychotropics impact on antiretroviral drugs causing toxicity or failure of the anti-HIV treatment. It is assumed that better adherence to ART through improved mental health would outweigh the negative impact psychotropic medications may have on the antiretroviral blood levels.

Appreciating the role of cytochrome P450, phase ii enzymes and transporters in psychopharmacology are highly vital in the drug management of sero-positive individuals. Many potential interactions based on cytochrome P450 metabolism, which is common to many psychotropics and the anti-retrovirals like the protease inhibitors, and the non-nucleoside reverse-transcriptase inhibitors have to be recognized. Protease inhibitors are the most problematic anti-retroviral agents that could cause drug interactions. They are metabolised by cytochrome 3A4 and are susceptible to lowering serum levels leading to viral resistance to anti-retrovirals. Ritonavir is a protease inhibitor that may inhibit psychotropics metabolized by cytochrome P450 3A4 and 2D6 isoenzymes. Efavirenz is a non-nucleoside reverse transcriptase 
inhibitor that causes vivid dreams, especially when initiated. Other HIV medications increase or decrease psychotropic blood levels via inhibition or induction of CYP isoenzymes $27.2 \%$ of all HIVinfected patients receiving medical care were identified as taking a psychotropic drug; antidepressants were the most common- $20.9 \%$ of all patients, followed by anxiolytics- $16.7 \%$, antipsychotics $-4.7 \%$, and psycho-stimulants-3\% [6].

\section{Antidepressants}

Both modern and older types of antidepressants are used in the treatment of depression associated with HIV/AIDS. Selective serotonin reuptake inhibitors (SSRIs) are indicated for major depression. Fluoxetine, Paroxetine, sertraline, and citalopram has demonstrated efficacy in the treatment of major depression associated with HIV/AIDS. Interactions with antiretrovirals are possible with all SSRIs by means of their potential to inhibit cytochrome P450 enzymes [60]. These SSRIs are metabolized by CYP isoenzymes. Therefore, there is the potential to increased levels of SSRIs when used in combination with anti-retrovirals that are enzyme inhibitors. When a patient is taking ritonavir or another protease inhibitor, starting dosages of SSRIs should be low.

The combination of fluoxetine and ritonavir has been shown to increase the concentration of ritonavir [61]. In a series of 5 cases of serotonin syndrome in patients taking fluoxetine and anti-retrovirals, the most common cause was ritonavir, which was believed to increase fluoxetine levels by inhibition of CYP2D6. One study has indicated no apparent interaction between ritonavir and escitalopram [62].

Three antidepressants considered to be relatively safe with HAART are mirtazapine, venlafaxine and duloxetine [25]. Mirtazapine has been shown to be effective in treating depression in HIV-infected patients and its side effects promoting appetite and sleep are advantageous for the infected. It is metabolized by CYP iso-enzymes, leaving the potential for interactions with CYP inhibitors like Ritonavir. Venlafaxine is a weak inhibitor of CYP 2D6.0ne drug-interaction study found that venlafaxine decreased the plasma concentration of indinavir [58]. Because Duloxetine is metabolized by CYP2D6 and 1A2, combining duloxetine with a potent CYP2D6 inhibitor like ritonavir can increase the severity of adverse effects. Tricyclic antidepressants are metabolized by 2D6 with other CYP450 enzymes involved secondarily and coadministration of ritonavir as well as other anti-retrovirals that inhibit these enzymes can increase their serum concentrations and pose the risk of toxicity.

\section{Anxiolytics}

Sero-positive patients are highly vulnerable to substance abuse and the use of benzodiazepines as anxiolytics needs special caution. Of the benzodiazepines, alprazolam, midazolam, and triazolam are dependent on CYP 3A4 for metabolism. Potent inhibitors of this CYP isoform, such as ritonavir, can decrease clearance of these drugs and result in over sedation and possibly death.

The benzodiazepines oxazepam, lorazepam, and temazepam are metabolized by glucuronidation. Drugs that increase the activity of glucuronidation, such as ritonavir, ornelfinavir, may lower the levels of these drugs. Benzodiazepine dosages may need to be increased because of ritonavir induction of the enzyme glucuronosyl transferase. Zopiclone and zolpidem are nonbenzodiazepine hypnotics designed to avoid drug dependence and daytime sedation, but they are metabolized by CYP3A4, leaving them vulnerable to interactions with enzyme inhibitors.

\section{Mood stabilisers}

Among the mood stabilisers, lithium is the least likely to have specific drug interactions with anti-retrovirals. It has a narrow therapeutic index and can be a potent delirient in a patient taking multiple medications who has underlying cognitive limitations. In HIV-infected patients, lithium has the potential to cause nausea, vomiting, diarrhoea, tremor, thyroid dysfunction, and kidney problems at therapeutic doses. Valproic acid does not appear to exhibit significant CYP-based drug interactions with antiretrovirals. Valproic acid may impair zidovudine metabolism through inhibition of glucuronidation, but this has not proven to have any clinical significance [63].

Carbamazepine is metabolized via CYP3A4 and induces its own metabolism. Such auto-induction and the potential for bonemarrow suppression make its use complicated. There is clinical evidence of carbamazepine toxicity resulting from its use in combination with CYP3A4 inhibitors, such as ritonavir. Lamotrigine has shown promise in the treatment of mood disorders and is indicated for treatment of bipolar disorder. It is not metabolized through the CYP system, but its concentration has been shown to decrease when used in combination with ritonavir [64].

\section{Antipsychotics}

Antipsychotic drugs are partially metabolised at cytochrome2DR. CYP inhibitors have the potential to increase the concentration of the antipsychotics, clozaril, and pimozide. Clozapine blood levels may be increased by ritonavir, increasing the risk of seizures and hypotension. Co-administration of pimozide and protease inhibitors is inadvisable due to risk of arrhythmia. For this reason, clozaril and pimozide have been contraindicated with anti-retrovirals with CYP inhibition, such as ritonavir. In addition, the potential for toxic increases by CYP inhibitors exist in other antipsychotics, including chlorpromazine, haloperidol, olanzapine, and risperidone [65].

Sero-positive patients are more vulnerable to extra pyramidal side effects and this may possibly due to basal ganglia damage. Atypical antipsychotic medications and HAART have been shown to cause clinically important dyslipidemia and metabolic dysregulation in a population at high baseline cardiovascular risk. The combined effects of concurrent use of these drug classes on lipids and other metabolic indices remain undetermined.

\section{Interactions with Substances of Abuse}

Substances of abuse can interact with HIV medications and many of the sero-positive patients suffer from current or past substance use disorder. Substances of abuse metabolized by CYP 
2D6 or 3A4-such as amphetamines, ketamine, heroin, cocaine, and gamma-hydroxybutyrate may cause toxic reactions in patients being treated with protease inhibitors. Inhaled marihuana has been proven to decrease the bio-availability of indinavir and nelfinavir [66]. The literature on this subject is tentative. Among patients who have a history of alcohol problems and are receiving antiretroviral treatment, alcohol consumption was associated with higher HIV RNA levels and lower CD4 counts [67]. When alcohol is regularly consumed by HIV-infected patients, especially those who are receiving HAART, it may have a substantial impact on HIV disease progression.

\section{Psycho-ethical aspects}

Some people act out anger about being HIV positive by having unprotected sex and failure of the protection may occur. Therapists have a dilemma when a patient diagnosed as HIV positive is reluctant to inform their partner for fear of damaging the relationship, and there are no clear guidelines about this. The General Medical Council says that disclosure of personal information about a patient without consent may be justified if failure to disclose may expose others to risk of death or serious harm.

There is a wide range of situations. There are people who claim to have no sexual partner, and others who will not disclose their sexual history. One individual disclosed the identity of his sexual partner, but refused to divulge his HIV status to her. One made the physician believe he had been honest with his wife, but he had not. In a fifth type, a wife was pregnant by the patient, so the foetus ran the risk of HIV probably the most difficult scenario. Doctors have to practise medical ethics but are not expected to be prophets of morality. That has to be left to others.

Sometimes elderly psychiatric patients who are medically ill refuse blood testing because they fear a HIV test being done without their knowledge; they need counselling and reassurances. Psychiatric patient who may have engaged in risky sexual behaviour and refuse HIV testing pose another dilemma. The parents of HIVpositive children may object to disclosure to them by the medical team, presenting an ethical dilemma. Current guidelines suggest that professionals have the authority to disclose the information to children if they are at significant risk.

\section{Summary}

HIV/AIDS involves psychiatric, medical and social dimensions, and a bio-psychosocial approach supporting patients, families and clinicians is to be adopted. All general psychiatrists need to be provided with a basic understanding of the co-morbid medical and psychiatric conditions that cause distress, morbidity and mortality to persons affected. HIV/AIDS specialists are bound to encounter psychiatric morbidity while caring for their patients and mental health professionals come across sero-positive patients and potentially high-risk individuals to HIV; effective liaison work between the two disciplines are highly beneficial for the patients. Experienced clinicians are the main life line for AIDS victims and that is probably the case with AIDS related psychiatric disorders. Now that HIV/AIDS patients are able to prolong their life spans to enjoy senior citizen status with the advent of newer medications, psycho-geriatricians should be prepared to care for their mental health needs.

Mental health professionals can make a valuable contribution in formulating strategies to increase the longevity and quality of life for people living with HIV/AIDS as well as to controlling the spread of the disease. Psychiatrists can also contribute to reducing the stigma associated with having HIV. Advanced ART has changed the old outlook of dying due to AIDS into living with AIDS. HAART has had dramatic effects and given a glimmer of hope of discovering a future cure. Such optimism has reduced suicidal tendencies among sero-positive patients. More research is required in HIV/AIDS population specifically in sub-Saharan Africa to better recognize the different needs of the population of this malady [68].

In developed countries, HIV clinics now witness patients recovering from long illnesses and gradually regaining new strength and confidence. The new lease with life also poses newer challenges for them in staying well. HAART has increased the life span and consequently, more sero-positive patients are coming to geriatric and psychogeriatric services. Success lies in the earlier detection and initiation of anti-retovirals, and mental health workers can make significant contributions in this arena. Psychiatrists can play an important supportive role in encouraging HIV screening of at-risk patients of unknown sero-status and in counselling such patients before, during, and after test results are known.HIV research has been one of the most successful stories of medical sciences. As a number of sufferers were wealthy and influential people, there was lavish funding to this crucial research and it is anticipated that in twenty years' time, HIV would be brought under medicinal control.

The connection between mind and body is inextricably woven into this viral condition and so is infectious disease speciality and AIDS psychiatry. HIV/AIDS and Borna virus disease in animals help to bring an infection-based model of schizophrenia into the realm of scientific imagination. HIV infection has indirect significance for schizophrenia research. Bradley Pearce argues that HIV-related encephalitis could engender a scenario for a viral aetiology of schizophrenia [69].

\section{Acknowledgement}

I am grateful to Dr Elizabeth Illing for the valuable contributions. No funding and no conflicts of interests.

\section{References}

1. Glenn J Treisman, Andrew F Angelino, Heidi E Hutton (2001) Psychiatric Issues in the Management of Patients with HIV Infection. JAMA 286(22): 2857-2864.

2. Cournos F, Mckinnon K (1997) HIV sero prevalence among people with severe mental illness in the United States: a critical review. Clin Psychol Rev 17(3): 259-269.

3. Rayment Michael, Asboe David, Sullivan K Ann (2014) HIV testing and management of newly diagnosed HIV. BMJ 349: 27-32.

4. May MJ Gompele M, Delpech V, Porter K, Orlon C, Kegg S, et al. (2014) Impact on life expectancy of HIV.1 positive individuals of CD4+ Cell count and viral load response to antiretroviral therapy. AIDS 28(8): 1193-1202. 
5. Mahy M, Autenrieth CS, Stanecki K, Wynd S (2014) Increasing trends in HIV prevalence among people aged 50 years and older: Evidence from estimates and survey data. AIDS 28: S453-S459.

6. Bing EG, Burnam MA, Longshore D (2001) Psychiatric disorders and drug use among human immunodeficiency virus-infected adults in the United States. Arch Gen Psychiatry 58(8): 721-728.

7. Chandra S Prabha, Desai Geetha, Ranjan Sanjev (2005) HIV \& Psychiatric Disorders. Indian J Med Res 121(4): 451-467.

8. Treisman J Glenn, Angelino F Andrew (2004) The Psychiatry of AIDS Baltimore: John Hopkins University Press, USA.

9. Eldred LJ, Wu AW, Chassion RE, Moore RD (1998) Adherence to antiretroviral and pneumocystitis prophylaxis in HIV disease. J Acquir Immune Defic Syndr Hum Retrovirol 18(2): 117-125.

10. Granville Grossman K (1987) Changing attitude to AIDS. British Journal of Hospital Medicine 38: 385-386.

11. Melvyn Freeman, Vikram Patel, Pamela Y Collins, Bertolote J (2005) Integrating mental health in global initiatives for HIV/AIDS. Br Psychiatry 187: 1-3.

12. (2006) Centers for Disease Control and Prevention, HIV/AIDS Surveillance Report, CDC. Atlanta, USA.

13. Hontelez JAC, Vlas de SJ, Baltussen R (2012) The impact of antiretrovira treatment on the age composition of the HIV epidemic in sub-Saharan Africa. AIDS 26: S19-S30.

14. Griffith JL, Gaby L (2005) Brief psychotherapy at the bedside: countering demoralization from medical illness. Psychosomatics 46(2): 109-116.

15. El Sadr W, Gettler J (1995) Unrecognized human immunodeficiency virus infection in the elderly. Arch Intern Med 155(2): 184-186.

16. Lekas HM, Schrimshaw EW, Siegel K (2005) Pathways to HIV testing among adults aged fifty and older with HIV/AIDS. AIDS Care 17(6): 674-687.

17. Phillips AN, Lee CA, Elford J, Webster A, Janossy G, et al. (1991) More rapid progression to AIDS in older HIV-infected people: the role of CD4+ T-cell counts. J Acquir Immune Defic Syndr 4(10): 970-975.

18. Balslev U, Monforte AD, Stergiou G, Antunes F, Mulcahy F, et al. (1997) Influence of age on rates of new AIDS-defining diseases and survival in 6546 AIDS patients. Scand J Infect Dis vol 29(4): 337-343.

19. Jiang H, N Xie, Cao B, Tan L, Fan Y, et al. (2013) Determinants of progression to AIDS and death following HIV diagnosis: a retrospective cohort study in Wuhan, China. PLoS One 8(12): e83078.

20. Bonnet F, Thiébaut R, Chêne G, Neau D, Pellegrin JL, et al. (2005) Determinants of clinical progression in antiretroviral-naive HIV-infected patients starting highly active antiretroviral therapy. HIV Med 6(3): 198 205.

21. Grabar, Kousignian I, Sobel A, Le Bras P, Gasnault J, et al. (2004) Immunologic and clinical responses to highly active antiretroviral therapy over 50 years of age. Results from the French Hospital Database on HIV. AIDS 18(15): 2029-2038.

22. Seigel K, Ravies VH, Gorey E (1998) Barriers and pathways to testing among HIV infected women. AIDS Educ Prev 10(2): 114-127.

23. Kelly JA, Murphy DA (1992) Psychological interventions with AIDS and HIV: prevention and treatment. J Consult Clin Psychol 60(4): 576-585.

24. Kennedy CA, Skurnick JH, Foley M, Louira DB (1995) Gender differences in HIV related psychological distress in heterosexual couples. AIDS Care 7: 533-538.

25. Fernandez Framcisco, Ruiz Pedro (2006) Psychiatric Aspects of HIV/ AIDS. Lippincott Williams \& Wilkins, New York, USA
26. Melvyn Freeman, Nkululekom, Nkomo, ZuhayrKafaar, Kevin Kelly (2008) Mental Disorder in People Living with HIV/Aids in South Africa. South African Journal of Psychology 38: 489-500.

27. Gala C, Pergami A, Catalan J, Durbano F, Musicco M, et al. (1993) The psychosocial impact of HIV infection in gay men, drug users and heterosexuals. Br J Psychiatry 163: 651-659.

28. Kalichman SC, Heckman T, Kochman A, Sikkema K, Bergholte J (2000) Depression and thoughts of suicide among middle aged and older persons living with HIV-AIDS. Psychiatr Serv 51(7): 903-907.

29. Sewell D (1996) Schizophrenia and HIV. Schizophrenia Bulletin 22(3): 465-473.

30. Ciesla A Jeffrey, Roberts JE (2001) Meta-analysis of the relationship between hiv infection and risk for depressive disorders. Am J Psychiatry 158(5): 725-730.

31. Riberio CMF, Gurgel WS, Luna JRG, Matos KJN, Souz FGM (2013) Is bipolar disorder a risk factor for HIV infection. J Affect Disord 146(1): 66-70.

32. Ellen SR, Judd FK, Mijch AM, Cockram A (1999) Secondary mania in patients with HIV infection. Aust N Z J Psychiatry. 33(3):353-360.

33. Atkinson JH, Grant I (1994) Natural history of neuropsychiatric manifestations of HIV disease. Psychiatr Clin North Am 17(1):17-33.

34. Kalichmanl SC, Kelly JA Johnson J (1994) Factors associated with risk for HIV infection among chronic mentally ill adults. Am J Psychiatry. 151(2): 275-280.

35. Lightfoot M, Rogers T, Goldstein R, Rotheram Borus MJ, May S, et al. (2005) Predictors of substance use, frequency and reduction among people living with HIV. Drug and alcohol Depend 77(2): 129-38.

36. Golding M, Perkins DO (1996) Personality disorder in HIV infection. International reviews in Psychiatry 8(2-3): 253-258.

37. Outsileri E, Meulen V, Riederer P (2001) Neurotransmission in HIV associated dementia: a short review. J Neural Transm (Vienna) 108(6): 767-775.

38. Lawrence DM, Major EO (2002) HIV-1 and the brain: connections between HIV-1-associated dementia neuropathology and neuroimunology. Microbes Infect 4(3): 301-308.

39. Clifford DB (2002) AIDS dementia. Med Clin North Am 86: 537-550.

40. Aylward EH, Henderer JD, McArthur JC, Brettschneider PD, Harris GJ, et al. (1993) Reduced basal ganglia volume in HIV-1-associated dementia: results from quantitative neuroimaging. Neurology 43(10): 2099-2104.

41. Nath A (2002) Human immunodeficiency virus (HIV) proteins in neuropathogenesis of HIV dementia. J Infect Dis 186(Suppl 2): S193-S198.

42. Sa MJ, Madeira MD, Ruela C, Volk B, Mota-Miranda A, Lecour H, et al. (2000) AIDS does not alter the total number of neurons in the hippocampal formation but induces cell atrophy: a stereological study. Acta Neuropathol 99(6): 643-653.

43. Reynolds A, Kammogne G, Kadiu I Gendelman HF (2008) HIV and the central nervous system In MA Chen and JM Gorman Comprehensive text book of AIDS psychiatry Oxford Publishing, New York, USA.

44. Cysique LAJ, Maruff P, Brew BJ (2006) Variable benefit in neuropsychological function in HIV- infected HAART treated patients. Neurology 66(9): 1447-1450.

45. Price RW, Spudich S (2008) Antiretroviral therapy and central nervous system HIV type 1 infection. J Infect Dis 15(Suppl 3): S294-S306.

46. Power C, Selnes OA, Grim JA, McArthur JC (1995) HIV Dementia Scale: a rapid screening test. J Acquir Immune DeficSyndr Hum Retrovirol 8(3): 273-278. 
47. Silberstein CH, Mc Kegney FP, O Dowd MA, Selwyn PA, Schoenbaum E, et al. (1987) A prospective longitudinal study of neuropsychological and psychosocial factors in asymptomatic individuals at risk for HTLVIII/LAV infection in a methadone program: preliminary findings. Int Neurosci 32(3-4): 669-676.

48. Reitan RM (1958) Validity of the trail making test as an indicator of organic brain damage. Percept Mot Skills 8(3): 271-276.

49. Valcour V, Shikuma C, ShiramizuB Watters M, Poff P, Selnes O, et al. (2004) Higher frequency of dementia in older HIV-1 individuals: the Hawaii aging with HIV-1 Cohort. Neurology 63(5): 822-827.

50. Sacktor N, McDermott MP, Marder K, Schifitto G, Selnes OA (2002) HIV-associated cognitive impairment before and after the advent of combination therapy. J Neurovirol 8(2): 136-142.

51. Lane F, Brasseur L, Musseault P (1994) Pain and HIV infection: a French national survey. Journal of Palliative Care 10: 95.

52. Penfold R, Clark AJM (1992) Pain Syndromes in HIV infection. Can J Anaesthesia 39(7): 724-730.

53. Maxwell S, Scheftner WA, Kessler HA, Busch K (1988) Manic syndrome associated with zidovudine [letter]. JAMA 259 (23): 3406.

54. Chen JL, Brocavich JM, Lin AYF (1992) Psychiatric disturbances associated with ganciclovir therapy. Ann Pharmacother 26(2): 193-195.

55. Hansen BA, Greenberg KS, Richter JA (1996) Ganciclovir-induced psychosis. NEJM 335(18): 1397.

56. Schiff HB (1997). More on ganciclovir-induced psychosis. NEJM 336 (16): 1190 .

57. Southworth MR, Dunlop SH (2000) Psychotic symptoms and confusion associated with intravenous ganciclovir in a heart transplant recipient. Pharmacotherapy 20(4): 479-483.

58. Shah SS, McGowan JP, Smith C, Blum S, Klein RS (2002) Comorbid conditions, treatment, and health maintenance in older persons with human immunodeficiency virus infection in New York City. Clin Infect Dis 35(10): 1238-1243.
59. Gleason LJ, Luque AE, Shah K (2013) Polypharmacy in the HIV-infected older adult population. ClinInterv Aging 8: 749-763.

60. Hemeryck A, Belpaire FM (2002) Selective serotonin reuptake inhibitors and cytochrome P-450 mediated drug-drug interactions: an update. Curr Drug Metab 3(1): 13-37.

61. Ouellet D, Hsu A, Qian J, Janet E. Lamm, John H Cavanaugh, et al. (1998) Effect of fluoxetine on pharmacokinetics of ritonavir. Antimicrob Agents Chemother 42(4): 3107-3112.

62. Gutierrez MM, Rosenberg J, Abramowitz W (2003) An evaluation of the potential for pharmacokinetic interaction between escitalopram and the cytochrome P450 3A4 inhibitor ritonavir. Clin Ther 25(4): 1200-10.

63. Levin GM, Nelson LA, DeVane CL, Preston SL, Eisele G, et al. (2001) A pharmacokinetic drug-drug interaction study of venlafaxine and indinavir. Psychopharmacol Bull 35(2): 62-71.

64. Liedtke M, Lockhart S, Rathbun R (2004) Anticonvulsant and antiretroviral interactions. Ann Pharmaco ther 38(3): 482-489.

65. Tseng AL, Foisy M (1999) significant interactions with new antiretrovirals and psychotropic drugs. Ann Pharmacother 33(4): 461-473.

66. Kosel BW, Aweeka FT, Benowitz NL, Shade SB, Hilton JF, et al. (2002) The effects of cannabinoids on the pharmacokinetics of indinavir and nelfinavir. AIDS 16(4): 543-550.

67. Samat HJ, Horton JN, Traphager TE, Lyon MS, Freedburg AK (2003) Alcohol consumption and HIV progression: are they related. Alcoholism 27(5): 862-867.

68. Bonaventura Cornel Mpondo (2016) HIV Infection in the Elderly: Arising Challenges Journal of Aging Research.

69. Peacrce Bradley (2003) Can Virus Cause Schizophrenia London. In: Peacrce Bradley (Ed.), KLUWER Academic Publishers, Netherlands, USA.
Creative Commons Attribution 4.0

International License

For possible submissions Click Here

\section{Submit Article}

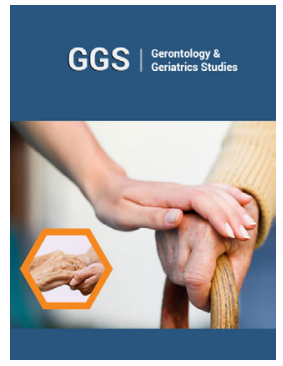

Gerontology \& Geriatrics Studies

Benefits of Publishing with us

- High-level peer review and editorial services

- Freely accessible online immediately upon publication

- Authors retain the copyright to their work

- Licensing it under a Creative Commons license

- Visibility through different online platforms 